\title{
Selecting the Most Adaptable Work Equipment
}

\author{
Tomaž Berlec - Janez Kušar* - Lidija Rihar - Marko Starbek \\ University of Ljubljana, Faculty of Mechanical Engineering, Slovenia
}

\begin{abstract}
Selecting the most suitable work equipment is a key factor in creating the value of products; therefore, the design and selection of work equipment are increasingly focused on its adaptability. The adaptability of work equipment with regards to flexibility and responsiveness is defined by its universality, mobility, modularity, compatibility and economy. This article presents a methodology of evaluating the adaptability of work equipment and a procedure for selecting work equipment with the maximum adaptability index (i.e. the optimal one) from a group of available work equipment. The results of designing and weighing the criteria of the target tree are presented, as well as the results of coarse and fine selection of the optimal CNC lathe, considering its expected adaptability.
\end{abstract}

Keywords: adaptability, flexibility, responsiveness, universality, mobility, modularity, compatibility, target tree

\section{INTRODUCTION}

The production programmes of small and medium enterprises are subject to continuous changes and ever increasing customer requests for the shortest possible delivery times, the best possible quality and the lowest possible product prices. Companies are faced with unstable demands regarding the types and quantities of products. Due to these demands, frequent changes of functions and the layout of work equipment are required. Problems with the adaptability of work equipment frequently occur.

Hernandez [1] asserted that adaptability is the potential of the company to carry out both the purchase of low-cost goal-oriented work equipment and the reconfigurations of it. Reinhar [2] and Zäh [3] understood adaptability to be an extension of flexibility. Nyhuis [4] said that adaptability is associated with additional costs of investment and consumption of time; however, the costs only apply when changes are carried out. Wiendahl [5] wrote that it is necessary to distinguish between five levels of adaptability: universality, mobility, modularity, compatibility and economy.

As a carrier of value creation, work equipment is the key factor of production. Today, the design and selection of work equipment are increasingly oriented towards its adaptability, mostly because of unreliable market forecasts [6] to [8].

The adaptability of work equipment is its ability to be adapted (at low cost) according to internal or external technological, structural, or organisational changes.

In general, adaptability consists of the flexibility and responsiveness of work equipment; this can be classified under universality, mobility, modularity, compatibility and economy.
Flexibility means that the work equipment is greater than needed with respect to the current functions, performance and accuracy. It allows the management of future, planned-in-advance scenarios. Additional functions are available and can be activated when needed. Work equipment must be able to adapt to new circumstances and new needs at low costs [9].

The responsiveness of work equipment is the capability of reacting to new circumstances that were not foreseen in the planning phase. Such a responsiveness is carried out by using its capability of being reconfigured. The desired result of responsiveness is modular, reconfigured work equipment.

When designing or selecting work equipment, it is necessary to take into account the requirements that must be met by it with regard to its technological functions and adaptability. An exact specification of the work equipment adaptability is required.

\section{COMPONENTS OF WORK EQUIPMENT ADAPTABILITY}

Adaptability of work equipment in the form of flexibility and the responsiveness of work equipment is defined by the universality, mobility, modularity, compatibility and economy of work equipment [5].

The universality of work equipment refers to its design and dimensions so that it can carry out various tasks.

Today, work equipment is highly universal; e.g. a work piece can be entirely processed on a turningmilling centre.

The mobility of work equipment refers to its ability to be moved if the structure or layout of the factory is changed. This mobility is influenced by its mass, size and transport mode. For work equipment that cannot be transported as a whole, it is essential 
that its components can be easily dismantled and reassembled afterwards.

The modularity of work equipment refers to modular design and standardisation of interfaces.

Interfaces have to fulfil the requirements of simple assembly and disassembly, precise positioning and high rigidity. Modularity must be carried out so that the buyers can change the work equipment by themselves.

The compatibility of work equipment refers to the possibility of its integration into the existing production structure.

The following interfaces are crucial for factory planning: control, IT and communication, mechanical, energy, user and material flow. In addition to connections, the term 'interface' also refers to the systems of the tools. The technology of connections is the decisive factor of compatibility. The producer of work equipment must sell only standard connections.

The extension of the available functions of work equipment always depends on the economy of doing so.

If extensions of functions were foreseen by the producer of the work equipment, the extension is usually economical; otherwise, it is not.

\section{SYSTEM OF ASSESSMENT OF WORK EQUIPMENT ADAPTABILITY}

The results of the assessment of work equipment adaptability will be presented as indices of adaptability of work equipment $\mathbf{K}$ with regard to universality, mobility, modularity, compatibility and economy.

The target tree procedure can be used to assess the adaptability of a piece of work equipment [10]. This is a comparative procedure that allows an assessment of at least two work equipment units. An essential part of the target tree procedure is the hierarchy of criteria, i.e. the logical classification and grouping of criteria.

The target tree in Fig. 1 shows a general tree of criteria for the assessing adaptability of work equipment.

A tree of criteria is the result of teamwork [11] and [12]. On the first level of the target tree, there is a target criterion corresponding to the searched target index value of work equipment adaptability. The following sub-criteria are on the second level of the target tree: universality, mobility, modularity, compatibility and economy [13]. On the third level of the target tree, there are the required basic criteria for which the schemes of fulfilment are made and from which the values of meeting the criteria $d_{i, j}$ can be found. The schematics regarding the fulfilment of criteria on the third level are usually set up in cooperation with the suppliers of work equipment. For each basic criterion on the third level of the target tree, a scheme regarding the fulfilment of the criterion must be formed and, on its basis, the value of fulfilment is determined.

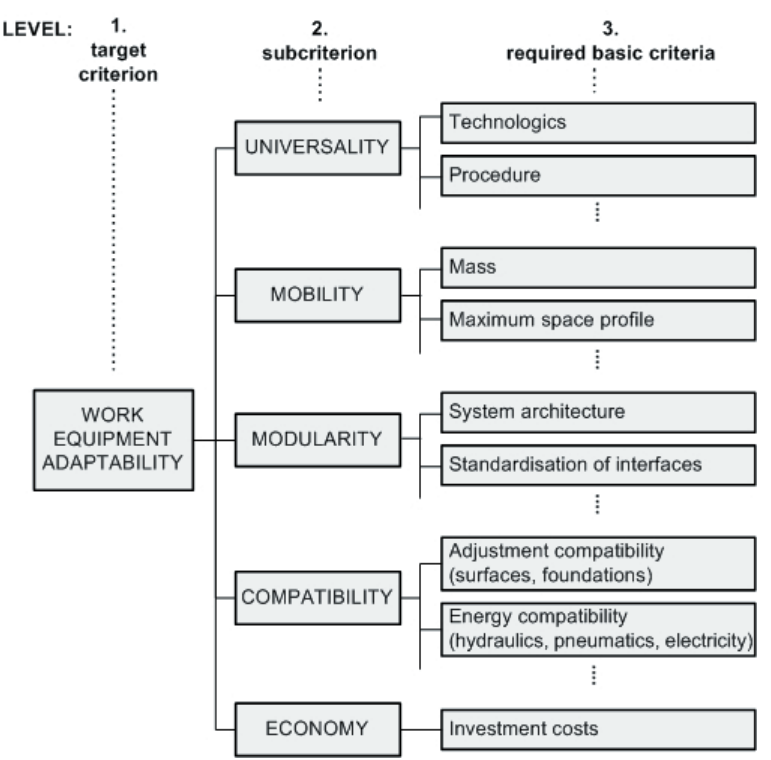

Fig. 1. Hierarchy of criteria for assessing adaptability of work equipment

Fig. 2 presents an example of a scheme regarding the fulfilment of the 'mass' criterion.

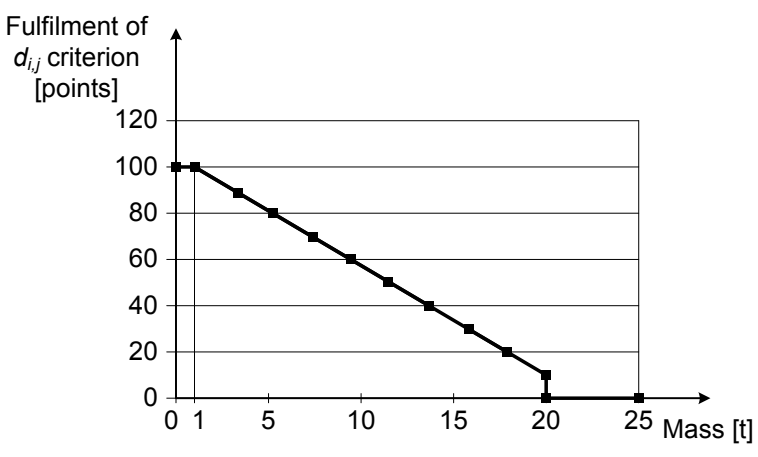

$d_{i, j}$ - the value of fulfilment of the ith criterion of the $j^{\text {th }}$ work equipment

Fig. 2. Scheme on fulfilment of the 'mass' criterion

It can be seen from Fig. 2 that if the mass of the work equipment is $1 \mathrm{t}$, the work equipment obtains 100 points, while it obtains only 10 points if its mass is $20 \mathrm{t}$.

The assessment of all criteria on the third level of the target tree is carried out in the same way as with the evaluation scale from 0 to 100 points. 
Adaptability criteria have different levels of importance; therefore, they must be assigned different weights, $u_{i}$, on all hierarchical levels.

When determining the weight factors for criteria of work equipment adaptability, it is necessary to take care that the relations between criteria make sense. The transitivity rule is valid here, i.e. if the first criterion has a larger weight than the second criterion:

$$
u_{1}>u_{2}
$$

and if the second criterion has larger weight than the third criterion:

$$
u_{2}>u_{3}
$$

then the first criterion has larger weight than the third criterion:

$$
u_{1}>u_{3} \text {. }
$$

The method of pair comparison is usually used for determining the weights of criteria [14].

It is necessary to consider the following when determining the weights of criteria, using the pair comparison method:

- the criterion that is more important than the other one is circled,

- if there are two equally important criteria, they are set within an oval,

- the weight of a criterion is a quotient between the number of its advantages and the total number of advantages,

- the sum of the weights of the criteria is 1 ,

- the criterion with the maximum weight is the most important and is placed as first.

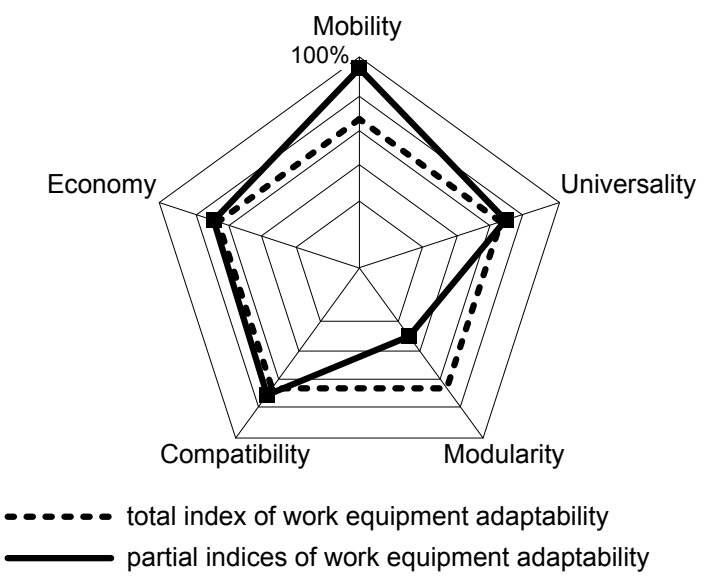

Fig. 3. Profile of work equipment adaptability

Known values of meeting the criteria on the third level of work equipment, $d_{i, j}$, and weights, $u_{i}$, allow the calculation of indices of work equipment adaptability regarding universality, mobility, modularity, compatibility, economy, and total index.

The results of determining the indices of work equipment adaptability are entered in a polar chart; such an example is shown in Fig. 3.

\section{SELECTION OF THE OPTIMAL WORK EQUIPMENT WITH RESPECT TO ADAPTABILITY}

The known system of evaluating work equipment adaptability allows the selection of the work equipment with the highest adaptability index (i.e. the optimal work equipment) from a group of available units.

An analysis of optimisation methods showed that the benefit-analysis method would be the most useful for a selection of the optimal work equipment [15]. The cost-benefit analysis is the most commonly used method for decision making: it is extremely simple to use and gives the target values of the benefits. This method requires data from suppliers of work equipment regarding the fulfilment of criteria, $d_{i, j}$, and the data from the buyer of the work equipment regarding weights of criteria, $u_{i}$.

After the creativity workshop had been carried out [16] regarding the weights of criteria, it was concluded that the selection would be carried out in two phases.

In the first phase, a coarse selection of a smaller group of work equipment suppliers (up to five) that best meet the requirements according to the defined criteria would be made. The basic data for a coarse selection would be provided by normalised data on the fulfilment of the required criteria in the smaller group of work equipment suppliers ( $d_{i, j}$ equals 0 or 1$)$.

In the second phase, a fine selection of work equipment would be carried out, i.e. the work equipment with the maximum benefit (maximum adaptability index) would be selected from the smaller group. Basic data for the fine selection would be provided by the data on the tests performed regarding the fulfilment of the $d_{i, j}$ criteria in the smaller group of suppliers ( 0 points $\leq d_{i, j} \leq 100$ points).

In theory, there are many possible algorithms for multi-objective optimization [17]. We decided to use the weighted sum method, because of its simplicity. 


\subsection{Coarse Selection of the Smaller Group of Work Equipment}

During coarse selection of work equipment, whether each unit meets the target tree criteria can be determined by using the data from the suppliers.

For the $j^{\text {th }}$ offered work equipment, an $n$ tuple of numbers regarding the fulfilment of criteria of the work equipment is created:

where:

$$
d_{1, j}, \ldots, d_{i, j}, \ldots, d_{n, j}
$$

$$
d_{i, j}=\left\{\begin{array}{ll}
1, & \begin{array}{l}
j^{\text {th }} \text { work equipment fulfils } \\
\text { the } i^{\text {th }} \text { criterion }
\end{array} \\
0, & j^{\text {th }} \text { work equipment doesn't } \\
\text { fulfil the } i^{\text {th }} \text { criterion }
\end{array},\right.
$$

where $d_{i, j}$ is a fulfilment of the $i^{\text {th }}$ criterion $(1 \leq i \leq m)$ on the $j^{\text {th }}$ work equipment $(1 \leq j \leq m)$.

On the basis of the data on the weights of criteria of a piece of work equipment $u_{i}$ (weights of criteria are normalised so that their sum is equal to 1 )

$$
u_{1}, \ldots, u_{i}, \ldots, u_{n}
$$

where $u_{i}$ is weight of the $i^{\text {th }}$ criterion of a piece of work equipment $(1 \leq i \leq n)$ and the values of criteria of the $j^{\text {th }}$ work equipment $\left(d_{i, j}\right)$, the sum of the products of weights and values of criteria of the $j^{\text {th }}$ work equipment is calculated as:

$$
u_{1} \cdot d_{1, j}+\ldots+u_{i} \cdot d_{i, j}+\ldots+u_{n} \cdot d_{n, j}
$$

This is adaptability or index of adaptability of the $j^{\text {th }}$ work equipment.

$$
k_{j}=\sum_{i=1}^{n} u_{i} \cdot d_{i, j},
$$

where $k_{j}$ is adaptability of the $j^{\text {th }}$ work equipment, $u_{i}$ the weight of the $i^{\text {th }}$ criterion and $d_{i, j}$ the value of the $i^{\text {th }}$ criterion of the $j^{\text {th }}$ work equipment.

It is convenient to write the calculation of adaptability of all offered work equipment units regarding their adaptability in a matrix form.

Three matrices must be created for this purpose:

- matrix of weights $\mathbf{U}$, which has one line and $n$ columns:

$$
\mathbf{U}=\left[u_{1}, \ldots, u_{i}, \ldots, u_{n}\right],
$$

- $\quad$ matrix $\mathbf{D}$ of values of functions, which has $n$ lines and $m$ columns:

$$
\mathbf{D}=\left[\begin{array}{ccccc}
d_{1,1} & \ldots & d_{1, j} & \ldots & d_{1, m} \\
\vdots & & \vdots & & \vdots \\
d_{i, 1} & \ldots & d_{i, j} & \ldots & d_{i, m} \\
\vdots & & \vdots & & \vdots \\
d_{n, 1} & \ldots & d_{n, j} & \ldots & d_{n, m}
\end{array}\right]
$$

- matrix $\mathbf{K}$ of adaptability of the offered work equipment, which has one line and $m$ columns:

$$
\mathbf{K}=\left[k_{1}, \ldots, k_{j}, \ldots, k_{m}\right] .
$$

Using the rule for multiplying matrices, we obtain the matrix of adaptability of the work equipment offered:

$$
\mathbf{K}=\mathbf{U} \cdot \mathbf{D} \text {. }
$$

By ranking elements of matrix $\mathbf{K}$, it is possible to obtain a smaller group of work equipment units for the fine selection.

\subsection{Fine Selection of Work Equipment}

Fine selection of work equipment starts with tests at suppliers of the smaller group of work equipment, and by taking notes on the values of fulfilment of the required criteria, $d_{i, j} *$.

An $n$-tuple of numbers, $d_{i, j}{ }^{*}$, regarding the fulfilment of the required functions is created for the $j$ th work equipment:

$$
d_{1, j}^{*}, \ldots, d_{i, j}^{*}, \ldots, d_{n, j}^{*}
$$

The fulfilment of the criteria is between: 0 points $\leq d_{i, j}{ }^{*} \leq 100$ points, where $d_{i, j}{ }^{*}$ is the value of fulfilment of the $i^{\text {th }}$ criterion of the $j^{\text {th }}$ work equipment (points).

On the basis of the data on weights of the required criteria of work equipment $u_{i}$, and fulfilment of the criteria of the $j^{\text {th }}$ work equipment of the smaller group $d_{i, j}{ }^{*}$, it is possible to create a sum of products of weight factors and criteria fulfilment values of the $j^{\text {th }}$ work equipment:

$$
u_{1} \cdot d_{1, j}^{*}+\ldots+u_{i} \cdot d_{i, j}^{*}+\ldots+u_{n} \cdot d_{n, j}^{*}
$$

This value is the adaptability of the $j^{\text {th }}$ work equipment:

$$
k_{j}^{*}=\sum_{i=1}^{n} u_{i} \cdot d_{i, j}^{*},
$$

where $k_{j}^{*}$ is adaptability of the $j^{\text {th }}$ work equipment in a smaller group. 
In the fine selection, it is convenient to write the calculation of the adaptability of the smaller group of work equipment in a matrix form. For this purpose, it is necessary to create two matrices:

- matrix $\mathbf{D}^{*}$ of the values of fulfilment of criteria of the smaller group of work equipment, which has $n$ lines and $m$ columns:

$$
\mathbf{D}^{*}=\left[\begin{array}{ccc}
d_{1,1}^{*} & d_{1, j}^{*} & d_{1, m}^{*} \\
\vdots & \vdots & \vdots \\
d_{i, 1}^{*} & d_{i, j}^{*} & d_{i, m}^{*} \\
\vdots & \vdots & \vdots \\
d_{n, 1}^{*} & d_{n, j}^{*} & d_{n, m}^{*}
\end{array}\right],
$$

- matrix $\mathbf{K}^{*}$ of adaptability $k_{j}^{*}$ of work equipment in the smaller group, which has one line and three columns:

$$
\mathbf{K}^{*}=\left[k_{1}^{*}, k_{2}^{*}, k_{3}^{*}\right] \text {. }
$$

By multiplying the matrices, we obtain the matrix of adaptability of the smaller group of work equipment:

$$
\mathbf{K}^{*}=\mathbf{U} \cdot \mathbf{D}^{*}
$$

By ranking elements of adaptability matrix $\mathbf{K}^{*}$, it is finally possible to obtain the work equipment with the maximum adaptability, i.e. with the maximum adaptability index:

$$
k_{\text {opt }}^{*}=\max _{j=1,2,3}\left\{k_{j}^{*}\right\} .
$$

\section{CASE STUDY OF SELECTING THE OPTIMAL CNC-LATHE WITH RESPECT TO ADAPTABILITY}

By conducting an analysis of the production programme over the previous five years, a company's management found that the production programme (considering types of products and their quantities) changed considerably from year to year.

The management decided that before buying work equipment in the future, it would be necessary to pay attention to the adaptability of it, in order to make the company more adaptable to the constant changes of the production programme. Using the defined criteria, it would be necessary to select work equipment that ensures the maximum adaptability.

After confirmation of the production programme for that particular year, it was found that the company urgently needed a new $\mathrm{CNC}$ lathe. A project team was established and tasked with selecting the $\mathrm{CNC}$ lathe that would ensure the maximum adaptability.

A creativity workshop was organised in the company [10], [11] and [16] with the aim of the team developing a target tree of criteria for assessing the adaptability of the $\mathrm{CNC}$ lathe. The results of

\begin{tabular}{|c|c|c|c|c|c|}
\hline \multirow{2}{*}{\multicolumn{2}{|c|}{ SUPPLIER of CNC lathe }} & \multicolumn{3}{|c|}{ Criterion fulfilled } & \\
\hline & & & & Yes & No \\
\hline \multirow{7}{*}{ Universality } & \multirow{4}{*}{ Intelligence } & Self-diagnosis - control & 1 & & \\
\hline & & Self-acquisition and processing of data & 2 & & \\
\hline & & Decentralised control & 3 & & \\
\hline & & Self-control - control of collision & 4 & & \\
\hline & \multirow{3}{*}{ Flexibility } & Functional flexibility - size & 5 & & \\
\hline & & Functional flexibility - function & 6 & & \\
\hline & & Flexibility of layout & 7 & & \\
\hline \multirow{4}{*}{ Mobility } & \multirow{4}{*}{ Design of work equipment } & Size & 8 & & \\
\hline & & Mass & 9 & & \\
\hline & & Robustness - stiffness for transport & 10 & & \\
\hline & & Simple assembly/disassembly & 11 & & \\
\hline \multicolumn{6}{|c|}{ 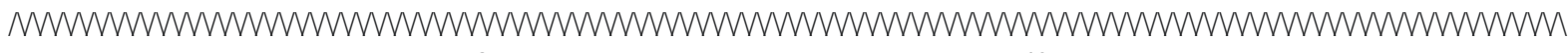 } \\
\hline \multirow{4}{*}{ Compatibility } & \multirow{4}{*}{$\begin{array}{l}\text { Effect of environment on } \\
\text { CNC lathe }\end{array}$} & Operating conditions - vibrations & 46 & & \\
\hline & & Operating conditions - temperature & 47 & & \\
\hline & & Operating conditions - humidity & 48 & & \\
\hline & & Self-sufficient supply - energy & 49 & & \\
\hline Economy & Investment costs & & 50 & & \\
\hline
\end{tabular}
development of the target tree of criteria are presented in Fig. 4.

Table 1. Questionnaire on fulfilment of criteria 


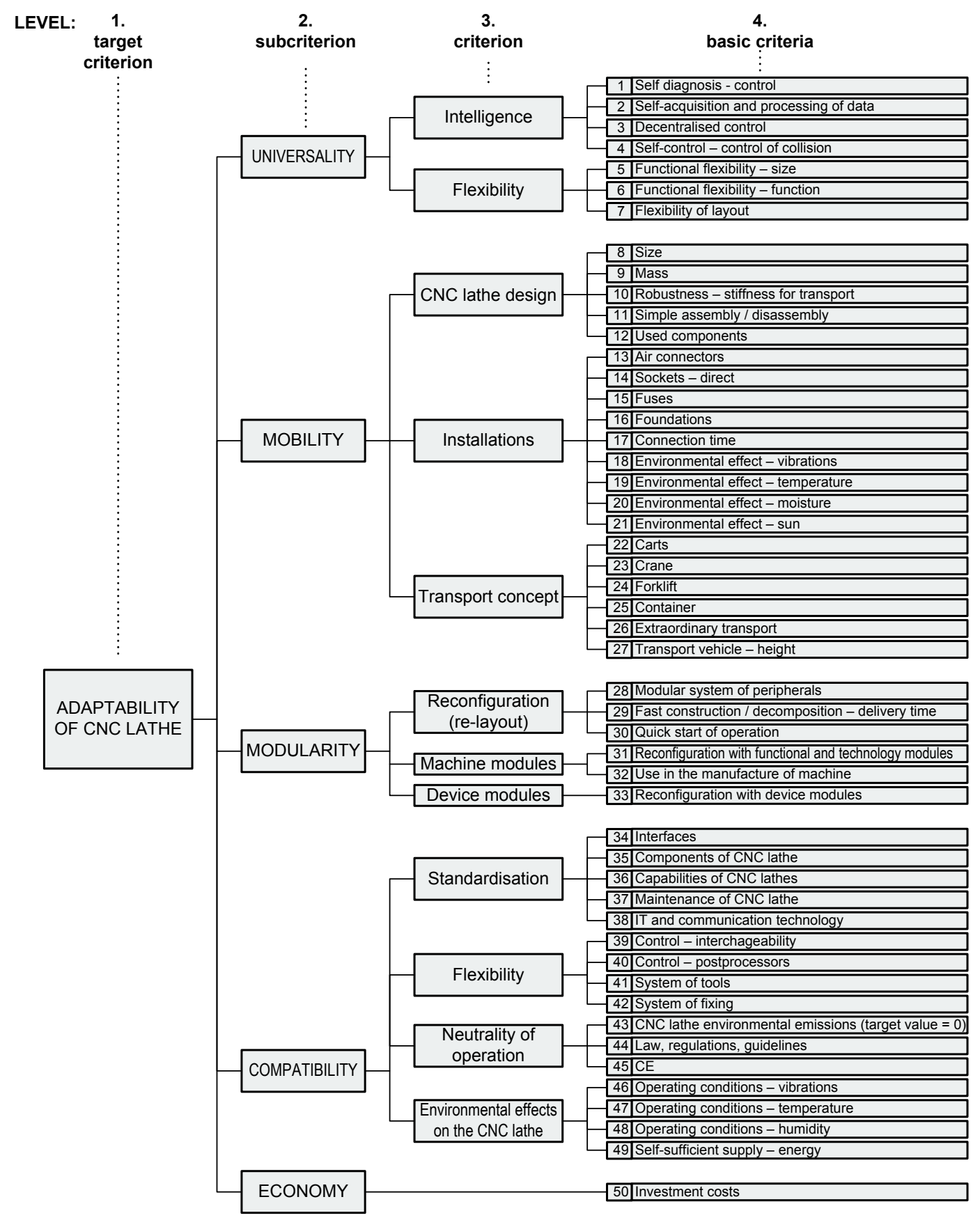

Fig. 4. The criteria for assessing the adaptability of a CNC lathe

The project team, in collaboration with suppliers of CNC lathes, created a fulfilment scheme for each criterion defined on the fourth level of the target tree (Fig. 4). Because the CNC lathe adaptability criteria had various levels of importance, the project team assigned different weights to them by using the paircomparison method.
Known criteria for the CNC lathe adaptability and known weights of criteria allowed the project team to carry out the coarse and fine selection of the $\mathrm{CNC}$ lathe.

In order to carry out the coarse selection of CNC lathes, the project team sent a questionnaire regarding the fulfilment of criteria for evaluating the adaptability 
Table 2. Adaptability matrix of nine $\mathrm{CNC}$ lathes

\begin{tabular}{|c|c|c|c|c|c|c|c|c|c|c|c|c|c|c|c|c|c|c|c|}
\hline \multirow{2}{*}{$\begin{array}{c}\text { Basic } \\
\text { criterion } \\
\text { no. }\end{array}$} & \multirow[b]{2}{*}{$\begin{array}{c}\text { Weights of } \\
\text { required } \\
\text { criteria } \\
u_{i}\end{array}$} & \multicolumn{2}{|c|}{ CNC-1 } & \multicolumn{2}{|c|}{ CNC-2 } & \multicolumn{2}{|c|}{ CNC-3 } & \multicolumn{2}{|c|}{ CNC-4 } & \multicolumn{2}{|c|}{ CNC-5 } & \multicolumn{2}{|c|}{ CNC-6 } & \multicolumn{2}{|c|}{ CNC-7 } & \multicolumn{2}{|c|}{ CNC-8 } & \multicolumn{2}{|c|}{ CNC-9 } \\
\hline & & $d_{i, 1}$ & $u_{i} \cdot d_{i, 1}$ & $d_{i, 2}$ & $u_{i} \cdot d_{i, 2}$ & $d_{i, 3}$ & $u_{i} \cdot d_{i, 3}$ & $d_{i, 4}$ & $u_{i} \cdot d_{i, 4}$ & $d_{i, 5}$ & $u_{i} \cdot d_{i, 5}$ & $d_{i, 6}$ & $u_{i} \cdot d_{i, 6}$ & $d_{i, 7}$ & $u_{i} \cdot d_{i, 7}$ & $d_{i, 8}$ & $u_{i} \cdot d_{i, 8}$ & $d_{i, 9}$ & $u_{i} \cdot d_{i, 9}$ \\
\hline 1 & 0.01 & 0 & 0.00 & 1 & 0.01 & 0 & 0.00 & 1 & 0.01 & 1 & 0.01 & 0 & 0.00 & 1 & 0.01 & 0 & 0.00 & 0 & 0.00 \\
\hline 2 & 0.02 & 0 & 0.00 & 1 & 0.02 & 0 & 0.00 & 1 & 0.02 & 1 & 0.02 & 0 & 0.00 & 1 & 0.02 & 0 & 0.00 & 0 & 0.00 \\
\hline 3 & 0 & 0 & 0.00 & 0 & 0.00 & 0 & 0.00 & 0 & 0.00 & 1 & 0.00 & 0 & 0.00 & 1 & 0.00 & 1 & 0.00 & 0 & 0.00 \\
\hline 4 & 0.05 & 0 & 0.00 & 0 & 0.00 & 0 & 0.00 & 0 & 0.00 & 1 & 0.05 & 0 & 0.00 & 1 & 0.05 & 0 & 0.00 & 0 & 0.00 \\
\hline 5 & 0.03 & 0 & 0.00 & 0 & 0.00 & 0 & 0.00 & 0 & 0.00 & 1 & 0.03 & 0 & 0.00 & 1 & 0.03 & 0 & 0.00 & 0 & 0.00 \\
\hline 6 & 0.02 & 0 & 0.00 & 0 & 0.00 & 0 & 0.00 & 0 & 0.00 & 1 & 0.02 & 0 & 0.00 & 1 & 0.02 & 0 & 0.00 & 0 & 0.00 \\
\hline 7 & 0.02 & 1 & 0.02 & 0 & 0.00 & 0 & 0.00 & 1 & 0.02 & 0 & 0.00 & 0 & 0.00 & 0 & 0.00 & 1 & 0.02 & 0 & 0.00 \\
\hline 8 & 0.015 & 1 & 0.02 & 1 & 0.02 & 1 & 0.02 & 0 & 0.00 & 1 & 0.02 & 1 & 0.02 & 1 & 0.02 & 1 & 0.02 & 1 & 0.02 \\
\hline 9 & 0.02 & 1 & 0.02 & 1 & 0.02 & 0 & 0.00 & 0 & 0.00 & 1 & 0.02 & 1 & 0.02 & 1 & 0.01 & 1 & 0.02 & 1 & 0.02 \\
\hline 10 & 0.025 & 0 & 0.00 & 1 & 0.03 & 0 & 0.00 & 1 & 0.03 & 1 & 0.03 & 1 & 0.03 & 1 & 0.03 & 1 & 0.03 & 1 & 0.03 \\
\hline 11 & 0 & 0 & 0.00 & 1 & 0.00 & 0 & 0.00 & 1 & 0.00 & 1 & 0.00 & 0 & 0.00 & 1 & 0.00 & 0 & 0.00 & 1 & 0.00 \\
\hline \multicolumn{20}{|c|}{ 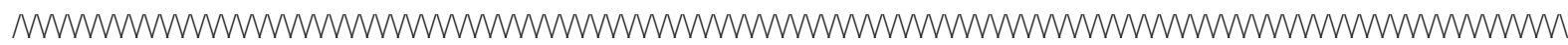 } \\
\hline 46 & 0.005 & 0 & 0.00 & 0 & 0.00 & 0 & 0.00 & 0 & 0.00 & 0 & 0.00 & 0 & 0.00 & 0 & 0.00 & 0 & 0.00 & 0 & 0.00 \\
\hline 47 & 0.005 & 0 & 0.00 & 0 & 0.00 & 0 & 0.00 & 0 & 0.00 & 0 & 0.00 & 1 & 0.01 & 0 & 0.00 & 0 & 0.00 & 0 & 0.00 \\
\hline 48 & 0 & 0 & 0.00 & 0 & 0.00 & 0 & 0.00 & 0 & 0.00 & 0 & 0.00 & 1 & 0.00 & 0 & 0.00 & 0 & 0.00 & 0 & 0.00 \\
\hline 49 & 0 & 0 & 0.00 & 0 & 0.00 & 0 & 0.00 & 0 & 0.00 & 0 & 0.00 & 0 & 0.00 & 0 & 0.00 & 0 & 0.00 & 0 & 0.00 \\
\hline 50 & 0.2 & 1 & 0.20 & 0 & 0.00 & 1 & 0.20 & 1 & 0.20 & 1 & 0.20 & 0 & 0.00 & 1 & 0.20 & 0 & 0.00 & 1 & 0.20 \\
\hline \multicolumn{2}{|c|}{$k_{j}=\sum_{i=1}^{50} u_{i} \cdot d_{i, j}$} & & 0.40 & & 0.47 & & 0.27 & & 0.41 & & 0.80 & & 0.20 & & 0.86 & & 0.29 & & 0.35 \\
\hline \multicolumn{2}{|c|}{$\begin{array}{l}\text { Rank of the offered } \\
\text { CNC lathes: }\end{array}$} & & 5. & & 3. & & 8. & & 4. & & 2. & & 9. & & 1. & & 7. & & 6. \\
\hline
\end{tabular}

Table 3. Adaptability matrix of three CNC lathes

\begin{tabular}{|c|c|c|c|c|c|c|c|c|}
\hline \multirow{3}{*}{$\begin{array}{l}\text { Basic } \\
\text { criterion } \\
\text { no. }\end{array}$} & \multirow{3}{*}{$\begin{array}{l}\text { Description of required criteria } \\
\text { of a CNC lathe: }\end{array}$} & \multirow{3}{*}{$\begin{array}{c}\text { Weights of } \\
\text { required } \\
\text { criteria } u_{i}\end{array}$} & \multicolumn{6}{|c|}{ Smaller group of CNC lathes $j=2,5,7$} \\
\hline & & & \multicolumn{2}{|c|}{ CNC-2 } & \multicolumn{2}{|c|}{ CNC-5 } & \multicolumn{2}{|c|}{ CNC-7 } \\
\hline & & & $d_{i, 2^{*}}$ & $u_{i} \cdot d_{i, 2}^{*}$ & $d_{i, 5}{ }^{*}$ & $u_{i} \cdot d_{i, 5^{*}}$ & $d_{i, 7^{*}}$ & $u_{i} \cdot d_{i, 7^{*}}^{*}$ \\
\hline 1 & Self-diagnosis - control & 0.01 & 0.50 & 0.01 & 0.90 & 0.01 & 1.00 & 0.01 \\
\hline 2 & Self-acquisition and processing of data & 0.02 & 0.50 & 0.01 & 0.90 & 0.02 & 1.00 & 0.02 \\
\hline 3 & Decentralised control & 0 & 0.20 & 0.00 & 0.80 & 0.00 & 0.80 & 0.00 \\
\hline 4 & Self-control - control of collision & 0.05 & 0.00 & 0.00 & 0.50 & 0.03 & 1.00 & 0.05 \\
\hline 5 & Functional flexibility - size & 0.03 & 0.20 & 0.01 & 0.40 & 0.01 & 1.00 & 0.03 \\
\hline 6 & Functional flexibility - function & 0.02 & 0.10 & 0.00 & 0.40 & 0.01 & 1.00 & 0.02 \\
\hline 7 & Flexibility of layout & 0.02 & 0.00 & 0.00 & 0.00 & 0.00 & 0.00 & 0.00 \\
\hline 8 & Size & 0.015 & 0.80 & 0.01 & 0.90 & 0.01 & 1.00 & 0.02 \\
\hline 9 & Mass & 0.02 & 0.60 & 0.01 & 0.70 & 0.01 & 0.50 & 0.01 \\
\hline 10 & Robustness - stiffness for transport & 0.025 & 1.00 & 0.03 & 0.90 & 0.02 & 0.90 & 0.02 \\
\hline 11 & Simple assembly/disassembly & 0 & 1.00 & 0.00 & 0.80 & 0.00 & 0.60 & 0.00 \\
\hline \multicolumn{9}{|c|}{ 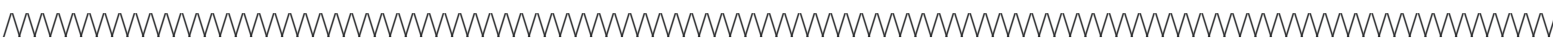 } \\
\hline 46 & Operating conditions - vibrations & 0.005 & 0.10 & 0.00 & 0.20 & 0.00 & 0.30 & 0.00 \\
\hline 47 & Operating conditions - temperature & 0.005 & 0.20 & 0.00 & 0.20 & 0.00 & 0.30 & 0.00 \\
\hline 48 & Operating conditions - humidity & 0 & 0.20 & 0.00 & 0.20 & 0.00 & 0.20 & 0.00 \\
\hline 49 & Self-sufficient supply - energy & 0 & 0.00 & 0.00 & 0.00 & 0.00 & 0.00 & 0.00 \\
\hline 50 & Investment costs & 0.2 & 0.15 & 0.03 & 0.40 & 0.08 & 0.90 & 0.18 \\
\hline \multicolumn{3}{|c|}{$k_{j}^{*}=\sum_{i=1}^{50} u_{i} \cdot d_{i, j}^{*}$} & & 0.45 & & 0.58 & & 0.75 \\
\hline \multicolumn{3}{|c|}{ RANK OF THE NARROWER GROUP of CNC lathes: } & \multicolumn{2}{|c|}{3.} & \multicolumn{2}{|c|}{2.} & \multicolumn{2}{|c|}{1.} \\
\hline
\end{tabular}


of CNC lathes to suppliers of CNC lathes. Table 1 shows part of the questionnaire.

After receiving answers from nine suppliers of CNC lathes, the project team made a coarse selection of the three $\mathrm{CNC}$ lathes that best fulfilled the required criteria. Using the known matrix $\mathbf{D}$ of fulfilment of the required criteria of the offered $\mathrm{CNC}$ lathes, and matrix $\mathbf{U}$ of criteria weights, the elements of adaptability matrix were calculated:

$$
\mathbf{K}=\mathbf{U} \cdot \mathbf{D} .
$$

Some results of the adaptability matrix are shown in Table 2.

After selecting a smaller group of CNC lathe suppliers, the project team, in collaboration with the suppliers, made a plan of tests regarding the fulfilment of the criteria to be performed at a particular supplier. During the tests, the project team members made notes on fulfilment of the required criteria on a particular CNC lathe. The lathe that best fulfilled a particular criterion received 100 points, while the other two lathes received penalty points.

Using the known matrix D* of achieved points, and matrix $\mathbf{U}$ of weights of criteria, the elements of the adaptability matrix were calculated:

$$
\mathbf{K}^{*}=\mathbf{U} \cdot \mathbf{D} *
$$

Some of the results of the adaptability matrix of the three $\mathrm{CNC}$ lathes from the smaller group are shown in Table 3.

By ranking the smaller group of three $\mathrm{CNC}$ lathes according to their adaptability (i.e. their adaptability index), the project team concluded that the company should buy the CNC-4 lathe that had the highest adaptability index.

\section{CONCLUSIONS}

This article defines the components of adaptability of work equipment. The system of adaptability assessment is also presented.

The limitation of the suggested method of selecting the most adaptable work equipment is the input data of working equipment available on the market.

The target tree is the basis of the system for assessing the adaptability of work equipment, showing the hierarchy of criteria for assessment of work equipment adaptability. A scheme regarding the fulfilment of each basic criterion of the target tree is designed. Criteria have different importance and thus different weights.
Known values of meeting the criteria and corresponding weights of criteria allow the calculation of an adaptability index of the observed work equipment. By first making a coarse and then a fine selection of the available work equipment using the adaptability method, it is possible to determine the work equipment with the maximum adaptability index.

Future work will be focused on better optimisation with the use of more accurate multiobjective optimization [17].

\section{REFERENCES}

[1] Hernandez, R. (2003). Systematik der Wandlungsfähigkeit in der Fabrikplanung. VDI Verlag, Düsseldorf. (in German)

[2] Reinhart, G., Berlak, J., Effert, C., Selke, C. (2002). Wandlungsfähige Fabrikgestaltung. Zeitschrift für wirtschaftlichen Fabrikbetrieb (ZWF), vol. 97, no. 1/2, p. 18-23. (in German)

[3] Zäh, M.F., Müller, N., Prasch, M., Sudhoff, W. (2004). Methodik zur Erhöhung der Wandlungsfähigkeit von Produktionssystemen. Zeitschrift für wirtschaftlichen Fabrikbetrieb (ZWF), vol. 99, no. 4, p. 173-177. (in German)

[4] Nyhuis, P., Heinen, T., Reinhart, G., Rimpau, C. (2008). Wandlungsfähige Produktionssysteme. Werkstattstechnik, vol. 98, no. 1/2, p. 85-91. (in German)

[5] Wiendahl, H.P., Reichardt, J., Nyhuis, P. (2009). Handbuch Fabrikplanung: Konzept, Gestaltung und Umsetzung wandlungsfähiger Produktionsstätten, Hanser Verlag, München. (in German), DOI: $10.3139 / 9783446423237$.

[6] Palčič, I., Buchmeister, B., Polajnar, A. (2010). Analysis of innovation concepts in Slovenian manufacturing companies. Strojniški vestnik - Journal of Mechanical Engineering, vol. 56, no. 12, p. 803-810.

[7] Anišić, Z., Krsmanović, C. (2008). Assembly initiated production as a prerequisite for mass customization and effective manufacturing, Strojniški vestnik - Journal of Mechanical Engineering, vol. 54, no. 9, p. 607-618.

[8] Božičković, R., Radošević, M., Ćosić, I., Soković, M., Rikalović. A. (2012). Integration of Simulation and Lean Tools in Effective Production Systems Case Study, Strojniški vestnik - Journal of Mechanical Engineering, vol. 58, no. 11, p. 642-652, DOI: DOI:10.5545/sv-jme.2012.387.

[9] Kušar, J., Berlec, T., Žefran, F., Starbek, M. (2010). Reduction of machine setup time. Strojniški vestnik Journal of Mechanical Engineering, vol. 56, no. 12, p. 833-845.

[10] Michalski, W.J. (2003). Six Sigma Tool Navigator: The Master Guide for Teams. Productivity Press, New York

[11] Rihar, L., Kušar, J., Gorenc, S., Starbek, M. (2012). Teamwork in the simultaneous product realisation. 
Strojniški vestnik - Journal of Mechanical Engineering, vol. 58, no. 9, p. 534-544, DOI:10.5545/ sv-jme.2012.420.

[12] Rihar, L., Kušar, J., Duhovnik, J., Starbek, M. (2010). Teamwork as a precondition for simultaneous product realization. Concurrent Engineering: Research and Applications, vol. 18, no. 4, p. 261-273.

[13] Reddy, B.S.P., Rao, C.S.P. (2011). Flexible Manufacturing System Modelling and Performance Evaluation Using AutoMod. International Journal of Simulation Modelling, vol. 10, no. 2, p.78-90, DOI:10.2507/IJSIMM10(2)3.176.
[14] Berkum, E.E.M. van (1987). Optimal Paired Comparison Designs for Factorial Experiments. Centrum voor wiskunde en informatica, Amsterdam.

[15] Boardman, A.E. (2006). Cost-Benefit Analysis and Practice. Prentice Hall, Upper Saddle River.

[16] Scherer, J. (2007). Kreativitätstechniken. Gabal Verlag, Offenbach. (in German)

[17] Zitzler, E. (1999). Evolutionary Algorithms for Multi Objective Optimization: Methods And Applications. $\mathrm{PhD}$ Thesis, Swiss Federal Institute of Technology, Zürich. 